\title{
ANALISIS JENIS DAN KANDUNGAN LOGAM PADA BATUAN BUANGAN DARI PERTAMBANGAN EMAS POBOYA
}

\author{
Rika Rahayu \& P.H Abram \\ Jurusan Pendidikan MIPA \\ Fakultas Keguruan dan Ilmu Pendidikan Universitas Tadulako Palu
}

\begin{abstract}
Metals has an important role for human life, especially in the industrial field. The purpose of this research is to find out the metal type and content in waste rock from the Poboya gold mine. The sampling technique is done by grabbing sampling, which is to take a lump of rock at a mining site. The analytical method used to determine the content and percentage of elements in rocks is XRF (X-Ray Fluorescence) spectrophotometry. The analysis results show that the metals contained in the waste rock from Poboya gold mining are Silicon (Si), Iron (Fe), Potassium (K), Aluminium (Al), Calcium (Ca), Titanium (Ti), Arsenic (As), Zirconium (Zr), Manganese (Mn), Strontium (Sr), Barium (Ba), Rubidium (Rb), Zinc (Zn), Niobium (Nb), Indium (In), Tin (Sn) and Stibium/Antimony (Sb). The highest percentage metals are Silicon 52.98\% and Iron 23.56\%. Based on these results, the high content of silica oxide and iron oxide in waste rock from Poboya has the potential as a basis to be used for making nano materials, especially nano silica and ferromagnetic materials.
\end{abstract}

Keywords: Metals, waste rocks, poboya gold mine, x-ray fluorescence (XRF)

\section{PENDAHULUAN}

Kerak bumi yang merupakan bagian paling penting dari bumi tersusun dari zat padat yang disebut dengan batuan. Batuan merupakan suatu agregat kohesif padat yang terbentuk secara alami dari satu atau lebih mineral/material (Mibei, 2014). Karakteristik dari beberapa jenis batuan bervariasi tergantung pada kondisi dan cara pembentukannya. Batuan yang terdapat di kerak bumi mengandung berbagai macam mineral yang berguna bagi manusia seperti emas, tembaga, perak dan lainnya (Hidayat dkk., 2014).

Mineral adalah bahan padat anorganik yang terdapat secara alamiah, terdiri dari satu atau lebih unsur kimiawi dalam perbandingan tertentu yang terdistribusi di kerak bumi (Handoko dkk., 2015). Sumber daya mineral atau bahan tambang telah disediakan oleh kerak bumi sebagai bagian dari mineral batuan dalam jumlah tertentu. Bahan galian tambang pada umumnya didapat di alam dalam keadaan terikat bersama berbagai logam dan unsur (mineral ikutan) lain secara fisik, bahkan bersenyawa secara kimiawi. Bijih logam biasanya terperangkap dalam batuan dan dalam bijih logam itu juga terdapat berbagai macam mineral (Sari, 2016).

Bentuk kelimpahan logam yang terdapat di kerak bumi bergantung pada reaktivitas logam yang bersangkutan, kelarutan garamnya, dan kemudahan garamya bereaksi dengan air (Sudarningsih dkk., 2017). Logam-logam yang tidak reaktif seperti emas, perak, dan platina, terdapat di alam sebagai unsurnya, sedangkan logam-logam yang agak reaktif terdapat sebagai sulfida misalnya CuS, PbS, dan ZnS. Logam- logam yang sedikit lebih reaktif diubah menjadi oksidanya, misalnya $\mathrm{MnO}_{2}, \mathrm{Al}_{2} \mathrm{O}_{3}$, dan $\mathrm{TiO}_{2}$, sedangkan logam-logam yang sangat reaktif membentuk garamnya, misalnya magnesium dan kalsium terdapat sebagai karbonat, sulffat, dan silikat (Pambudi \& Suprapto, 2018).

Sumber daya mineral jika diolah akan menghasilkan logam dan berbagai bahan keperluan proses industri untuk menunjang kehidupan manusia (Sari, 2016). Unsur-unsur seperti besi, tembaga dan alumunium banyak dimanfaatkan dalam dunia industri. Contohnya logam besi dimanfaatkan untuk tiang listrik, jembatan, kerangka bangunan dan sebagainya. Tembaga dimanfaatkan dalam industri, terutama dalam indusri elektroplating, tekstil, dan industri logam, sebagai material dasar dalam perlatan listrik, perhiasan, dan untuk keperluan lainnya. Sedangkan alumunium dalam industri rumah tangga digunakan untuk peralatan dapur, dalam industri makanan, kaleng minuman dan lain sebagainya (Alimin dkk., 2016).

Mineral yang terdapat di alam dapat mempunyai nilai ekonomis karena didapatkan dalam jumlah yang besar (Ali dkk., 2019). Untuk mendapatkan bahan mineral tersebut, manusia perlu melakukan penambangan. Pertambangan adalah rangkaian kegiatan dalam rangka upaya pencarian, penambangan, pegolahan, pemanfaatan dan penjualan bahan galian yang dilakukan baik secara tradisional maupun cara modern (Wawo dkk., 2017).

Pertambangan emas rakyat Poboya yang terletak di Provinsi Sulawesi Tengah, Kota Palu, Kecamatan Mantikulore salah satunya yang menyimpan sumber daya alam mineral berlimpah termasuk bahan galian (tambang) yang meliputi 
emas, perak, tembaga dan lain-lain (Janat dkk., 2017). Pertambangan dilakukan manusia dengan menggali, mengambil, dan mengolah sumber daya alam yang terdapat di perut bumi untuk memenuhi sebagian kebutuhan manusia (Nurhayati dkk., 2017).

Batuan yang terdapat di suatu wilayah pertambangan memiliki karakteristik dan komposisi berbeda satu dengan lainnya yang membuat batuan dapat diidentifikasi (Ardiansyah dkk., 2015). Oleh karena itu, penting melakukan analisis untuk mengetahui kandungan logam yang terdapat pada batuan di suatu wilayah pertambangan, seperti batuan yang ada di pertambangan emas rakyat Poboya yang memiliki warna cenderung kemerahan untuk selanjutnya dapat diketahui kelimpahan logam yang pada batuan di daerah pertambangan tersebut serta pemanfaatannya (Basuki dkk., 2017).

Salah satu metode yang dapat digunakanuntuk menganalisis kandungan logam pada sampel yaitu dengan menggunakan metode spektrometer X-Ray Fluorescence (XRF) (Balasubramanian \& Muthukumaraswamy, 2016). Penggunaan metode X-Ray Fluorescence ini berdasarkan pertimbangan bahwa teknik ini mempunyai limit deteksi hingga satuan part per million (ppm). Selain itu metode XRF mempunyai beberapa keuntungan diantaranya biaya relativ murah, multielemental, analisisnya cepat dan hasil analisisnya bersifat kualitatif dan kuantitatif (Kim \& Choi, 2019).

Berdasarkan uraian tersebut, maka peneliti tertarik menggunakan Metode X-Ray Fluorescence (XRF) untuk mengidentifikasi jenis dan menentukan kadar logam yang terkandung pada batuan buangan dari pertambangan emas rakyat Poboya.

\section{METODE PENELITIAN}

Alat yang digunakan pada penelitian ini yaitu palu-palu, lumpeng dan alu, cawan porselin, ayakan 70 mesh, oven, neraca analitik, desikator, serta seperangkat alat XRF.

Bahan yang digunakan pada penelitian ini yaitu batuan dari pertambangan emas rakyat Poboya dan aquades.

\section{Pengambilan sampel batuan}

Sampel batuan diambil dari pertambangan emas rakyat Poboya bagian $B$ yaitu batuan yang memiliki karakteristik berwarna kemerahan. Pengambilan sampel batuan di lapangan dengan cara grab sampling, yaitu mengambil bongkah batuan di lokasi pemanbangan (Wijaya dkk., 2016). Sampel batu yang telah diambil dicuci dengan aquades kemudian dikeringkan pada suhu ruang selama 24 jam (Handoko dkk., 2015).

Preparasi sampel batuan
Sampel batuan yang telah diambil di hancurkan menjadi bagian kecil menggunakan palu-palu. Selanjutnya dikeringkan di dalam oven pada suhu 110 oC selama 6 jam. Setelah itu, sampel digerus menggunakan lumpeng dan alu, kemudian diayak menggunakan ayakan 70 mesh. Sampel batuan lalu disimpan di wadah bersih dan kering (Karyasa, 2013).

\section{Analisis kadar air}

Cawan kosong dimasukkan ke dalam oven pada suhu $110 \mathrm{oC}$ selama 1 jam, didinginkan di dalam desikator selama 15 menit, lalu ditimbang (W3). Kemudian sebanyak 10 gram sampel batuan 70 mesh dimasukkan ke dalam cawan, lalu ditimbang (W1), kemudian dikeringkan di dalam oven pada suhu $1100 \mathrm{C}$ selama 2 jam, setelah itu didinginkan dalam desikator dan ditimbang menggunakan neraca analit (W2). Prosedur ini dilakukan hingga diperoleh berat konstan. Kemudian ditentukan kadar airnya dengan menggunakan persamaan berikut (BSN, 2008):

dengan:

$$
\mathrm{w}=\frac{\mathrm{W}_{1}-\mathrm{W}_{2}}{\mathrm{~W}_{2}-\mathrm{W}_{3}} \times 100 \%
$$

w : Kadar air (\%)

W1 : Berat cawan dan batu basah (gram)

W2 : Berat cawan dan batu kering (gram)

W3 : Berat cawan (gram)

(W1 -W2): Berat air

(W2 -W3): berat batu kering (gram)

\section{Analisis kandungan logam}

Sampel batuan hasil preparasi dianalisis menggunakan instrumen XRF (X-Ray Fluorescence) yang bertujuan untuk mengidentifikasi jenis dan menentukan kadar logam yang terkandung di dalam sampel batuan menggunakan radiasi sinar- $X$ yang diserap dan dipantulkan oleh sampel. Data yang diperoleh dari XRF berupa data komposisi dan persentase unsur yang terkandung dalam sampel batuan (Alimin dkk., 2016).

\section{HASIL DAN PEMBAHASAN}

\section{Pengambilan dan preparasi sampel batuan}

Pengambilan sampel batuan dilakukan dengan cara grab sampling yaitu mengambil Volume, 6, No. 1, 2017, pp-pp Jurnal Akademika Kimia sampel berupa bongkahan batuan di lokasi pertambangan (Wijaya dkk., 2016). Sampel batuan diambil di pertambangan emas rakyat Poboya bagian $B$. Secara magaskopik sampel batuan memiliki karakteristik berwarna kemerahan seperti pada gambar 1, ukuran batu berkisar antara 5-10 cm, memiliki tekstur berupa porfiroanfantik, holokristalin, struktur massif, dengan komposisi 
berupa feldsbar, kuarsa, hematit, amfibol, dan piroksen (Utami dkk., 2016).

Metode grab sampling merupakan teknik sampling dengan cara mengambil bagian (fragmen) yang berukuran besar dari suatu material yang mengandung materialisasi secara acak (tanpa seleksi khusus). Tingkat ketelitian sampling pada metode ini relatif mempunyai bias yang cukup besar (Wijaya dkk., 2016).

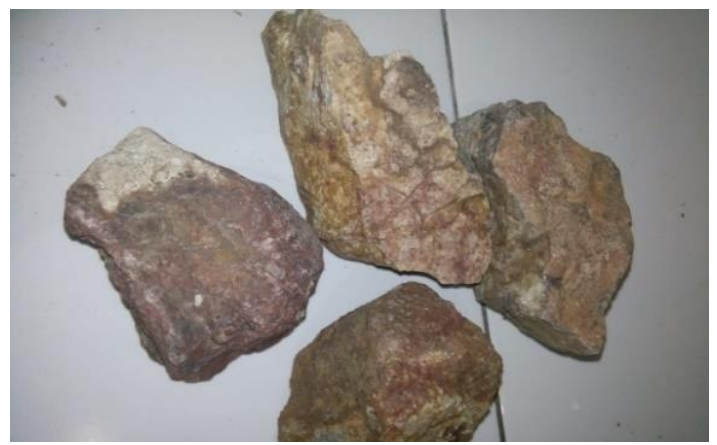

Gambar 1. Sampel batuan

\section{Kadar air}

Kadar air pada batuan adalah perbandingan berat air yang mengisi rongga pori material batuan terhadap berat partikel padatnya. Kadar air dalam suatu material digunakan untuk menyatakan hubungan antara fase udara, air, dan butiran padat yang berada dalam volume material (BSN, 2008).

Kadar air yang diperoleh yaitu masing-masing $0,4298 \%$, 0,4328\%, dan 0,4369\% sehingga diperoleh kadar air rata-rata sebesar $0,43 \%$.

Batuan tersusun dari berbagai mineral dan mempunyai sifat kelistrikan (resistivitas). Jumlah kadar air berpengaruh terhadap nilai resistivitas. Semakin besar kadar air yang terkandung dalam batuan maka nilai resistivitasnya akan semakin menurun. Resistivitas batuan adalah hambatan dari batuan terhadap aliran listrik. Resistivitas batuan dipengaruhi oleh porositas, kadar air, dan mineral. Beberapa batuan tersusun dari satu jenis mineral saja, sebagian kecil lagi dibentuk oleh gabungan mineral, dan bahan organik serta bahan vulkanik (Setiadi dkk., 2016)
Analisis jenis dan kadar logam pada
batuan menggunakan XRF
Analisis yang dilakukan untuk mengidentifikasi

Analisis yang dilakukan untuk mengidentifikasi
andungan senyawa yang terdapat dalam batuan dari pertambangan emas rakyat Poboya dilakukan dengan menggunakan XRF (X-Ray Fluorescence). Spektroskopi XRF merupakan teknik untuk mengganalisis unsur suatu bahan menggunakan spektrometer dari peristiwa efek fotolistrik yang berupa penyinaran sinar- $X$ ke sampel (Balasubramanian \& Muthukumaraswamy, 2016). Teknik ini banyak digunakan dalam analisis batuan ataupun mineral. Unsur dapat ditentukan keberadaannya secara langsung tanpa standar. Hasil keseluruhan dari karakterisasi sampel tersebut berupa data secara kualitatif dan kuantitatif (Li dkk., 2017). Adapun hasil analisis yang diperoleh dapat dilihat pada tabel 1 dan 2 :

Tabel 1. Komposisi batuan dalam bentuk

\begin{tabular}{ccc}
\hline No. & Senyawa & Persentase (\%) \\
\hline 1. & $\mathrm{SiO}_{2}$ & 67,76 \\
\hline 2. & $\mathrm{Fe}_{2} \mathrm{O}_{3}$ & 14,15 \\
\hline 3. & $\mathrm{Al}_{2} \mathrm{O}_{3}$ & 6,86 \\
\hline 4. & $\mathrm{~K}_{2} \mathrm{O}$ & 4,26 \\
\hline 5. & $\mathrm{CaO}$ & 3,24 \\
\hline 6. & $\mathrm{TiO}_{2}$ & 2,31 \\
\hline 7. & $\mathrm{P}_{2} \mathrm{O}_{5}$ & 0,55 \\
\hline 8. & $\mathrm{As}_{2} \mathrm{O}_{3}$ & 0,245 \\
\hline 9. & $\mathrm{MnO}$ & 0,175 \\
\hline 10 & $\mathrm{ZrO}_{2}$ & 0,160 \\
\hline 11. & $\mathrm{SrO}$ & 0,133 \\
\hline 12. & $\mathrm{BaO}^{2} \mathrm{Rb}_{2} \mathrm{O}$ & 0,072 \\
\hline 13. & $\mathrm{ZnO}^{2}$ & 0,0348 \\
\hline 14. & $\mathrm{Nb}_{2} \mathrm{O}_{5}$ & 0,0238 \\
\hline 15. & $\mathrm{In}_{2} \mathrm{O}_{3}$ & 0,0188 \\
\hline 16. & $\mathrm{SnO}_{2}$ & 0,0058 \\
\hline 17. & & 0,0052 \\
\hline
\end{tabular}


Tabel 2. Komposisi batuan dalam bentuk unsur

\begin{tabular}{ccc}
\hline No. & Unsur & Persentase (\%) \\
\hline 1. & $\mathrm{Si}$ & 52,98 \\
\hline 2. & $\mathrm{Fe}$ & 23,56 \\
\hline 3. & $\mathrm{~K}$ & 7,23 \\
\hline 4. & $\mathrm{Al}$ & 5,72 \\
\hline 5. & $\mathrm{Ca}$ & 5,00 \\
\hline 6. & $\mathrm{Ti}$ & 3,08 \\
\hline 7. & $\mathrm{P}$ & 0,672 \\
\hline 8. & $\mathrm{As}$ & 0,498 \\
\hline 9. & $\mathrm{Zr}$ & 0,317 \\
\hline 10 & $\mathrm{Mn}$ & 0,311 \\
\hline 11. & $\mathrm{Sr}$ & 0,302 \\
\hline 12. & $\mathrm{Ba}$ & 0,131 \\
\hline 13. & $\mathrm{Rb}$ & 0,087 \\
\hline 14. & $\mathrm{Zn}$ & 0,052 \\
\hline 15. & $\mathrm{Nb}$ & 0,0351 \\
\hline 16. & $\mathrm{In}$ & 0,0119 \\
\hline 17. & $\mathrm{Sn}$ & 0,0103 \\
\hline 18. & $\mathrm{Sb}$ & 0,0103 \\
\hline \hline
\end{tabular}

Hasil pengukuran berdasarkan tabel 1 dan tabel 2 memperlihatkan unsur terbanyak yang terkandung dalam batuan dari pertambangan emas Poboya yaitu secara berurut yaitu Silikon (Si) 52,98\%, Besi $(\mathrm{Fe}) 23,56 \%$, Kalium (K) 7,23\%, Alumunium (Al) 5,72\%, Kalsium (Ca) 5,00\%, dan Titanium (Ti) $3,08 \%$. Serta mineral oksida terbanyak secara berurut yaitu Silikon dioksida
(SiO2) $67,76 \%$, Besi(III) osida (Fe2O3) $14,15 \%$, Alumunium oksida (Al2O3) 6,86\%, Kalium oksida (K2O) 4,26\%, Kalsium oksida ( $\mathrm{CaO}$ ) 3,24\%, dan Titanium dioksida (TiO2) 2,31\%. Persentase kadar logam dan senyawa terbanyak pada batuan ditunjukkan oleh gambar 2 .

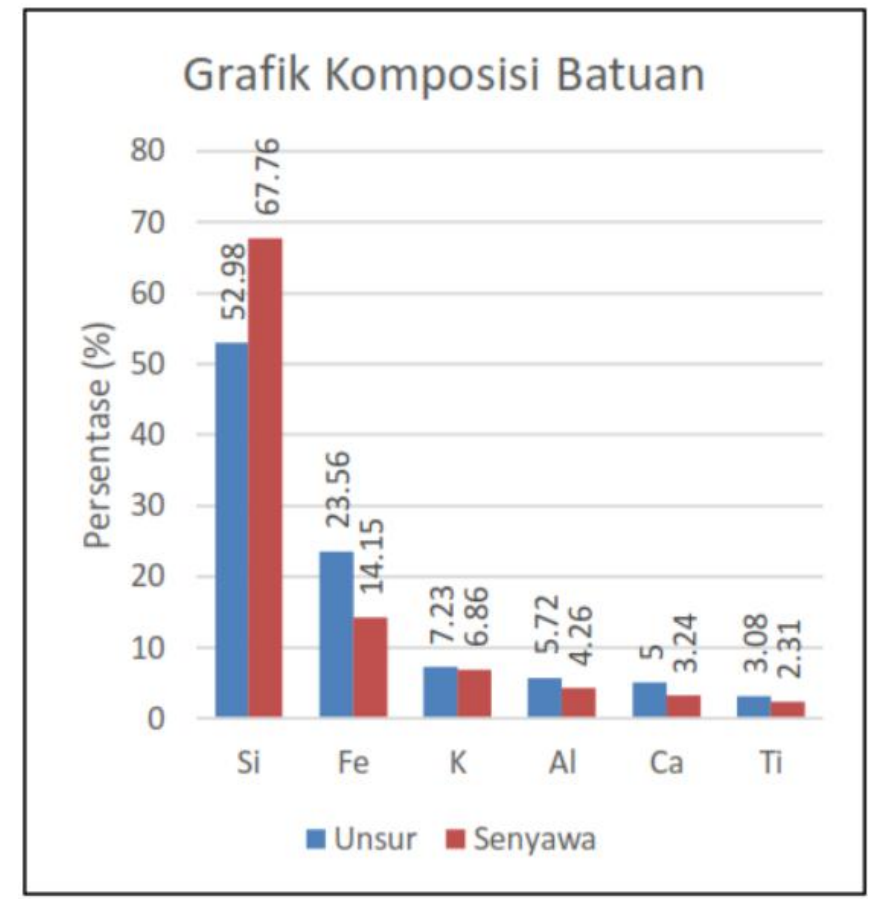

Gambar 2. Grafik komposisi batuan

Terdapat $67,76 \%$ mineral silika oksida pada batuan karena
$90 \%$ mineral pembentuk batuan adalah dari kelompok mineral silika, yang merupakan persenyawaan antara 
silikon dan oksigen dengan beberapa unsur logam. Hampir 90\% dari berat kerak bumi dan hamper $100 \%$ dari mantel bumi terdiri dari mineral silika. Silika merupakan bagian utama yang membentuk batuan baik sedimen, batuan beku maupun batuan malihan (Noor, 2012).

Kadar besi ( $\mathrm{Fe}$ ) tinggi pada batuan yaitu $23,56 \%$, hal ini disebabkan karena unsur besi dominan kelimpahannya di alam dibandingkan dengan logam lain termasuk dalam batuan. Kandungan besi oksida juga cukup tinggi yaitu Fe2O3 sebesar 14,60\%. Fe2O3 (Hematit) merupakan salah satu mineral yang paling melimpah di permukaan bumi maupun kerak bumi. Mineral ini merupakan mineral pembentuk batuan yang umumnya ditemukan pada batuan sedimen, metamorf, dan batuan beku (Jamaluddin \& Umar, 2018).

Selain itu, juga ditemukan mineral alumina (Al2O3) sebesar $6,86 \%$ dan $\mathrm{K} 2 \mathrm{O}$ sebesar $4,26 \%$. Kandungan $\mathrm{Al} 2 \mathrm{O} 3$ dan $\mathrm{K} 2 \mathrm{O}$ yang tinggi ini menunjukkan bahwa ciri kimia mineral utama pembentuk batuan seperti mineral feldspar, mika dan lempung yang kaya akan $\mathrm{Al} 2 \mathrm{O} 3$ dan $\mathrm{K} 2 \mathrm{O}$ masih tetap bertahan. Kandungan unsur-unsur ini, secara umum, terutama yang immobile ( $\mathrm{Ti}, \mathrm{Mg}$, dan $\mathrm{Fe}$ ) menunjukkan bahwa batuan tersebut berasal dari aktivitas magma (Qodri \& Putra, 2018).

Tingginya kandungan silika oksida dan besi oksida pada batuan dari pertambangan Poboya berpotensi dijadikan sebagai bahan dasar pembuatan nano material terutama nano silika dan sebagai bahan dasar pembuatan material ferromagnetik (Jamaluddin \& Umar, 2018).

\section{KESIMPULAN DAN UCAPAN TERIMA KASIH}

\section{Kesimpulan}

Logam-logam yang terkandung pada batuan buangan dari pertambangan Poboya beserta yaitu Silikon (Si), Besi (Fe), Kalium (K), Alumunium (Al), Kalsium (Ca), Titanium (Ti), Arsen (As), Zirkonium (Zr), Mangan (Mn), Stronsium (Sr), Barium (Ba), Rubidium (Rb), Seng (Zn), Niobium (Nb), Indium (In), Timah (Sn), dan Stibium/Antimon (Sb). Dengan persentasi logam terbanyak yaitu Silikon 52,98 \% dan Besi 23,56 \%. Tingginya kandungan silika oksida dan besi oksida pada batuan dari pertambangan Poboya berpotensi dijadikan sebagai bahan dasar pembuatan nano material terutama nano silika dan material ferromagnetik.

\section{Ucapan Terima Kasih}

Penulis mengucapkan terima kasih kepada Bapak Paulus Hengky Abram yang telah memberikan saran dan masukan untuk tulisan ini. Kepada laboran laboraturium Kimia FKIP UNTAD, Terima kasih atas bantuan kepada penulis selama melaksanakan penelitian.

\section{DAFTAR PUSTAKA}

[1] Ali, R. K., Qadaryati, N., \& Widadi, S. (2019). Analisis kualitas untuk optimasi pemanfaatan potensi sumber daya mineral non logam dan batuan di Kecamatan Lumbir, Kabupaten Bayumas. TEKNIK, 40(3), 161-168.

[2] Alimin, Maryono, \& Putri, S. E. (2016). Analisis kandungan mineral pasir pantai Losari Kota Makassar menggunakan XRF dan XRD. Jurnal Chemica, 17(2), 19-23.

[3] Ardiansyah, M., Farida, M., \& Irfan, U. R. (2015). Studi provenance batu pasir formasi Walanae daerah Lalebata Kecamatan Lamuru Kabupaten Bone Provinsi Sulawesi Selatan. Geosains, 11(01), 13-18. Volume, 9, No. 1, 2020, pp-pp Jurnal Akademika Kimia

[4] Balasubramanian, G., \& Muthukumaraswamy, S. A. (2016). On the empirical study of elemental analysis and metal testing using XRF spectrum analysis algorithm. Internastional Journal of Engineering and Applied Scciences, 3(1), 61-67.

[5] Basuki, R. A., Ardi, N. D., \& Iryanti, M. (2017) Analisis sebaran mineral logam pada sedimentasi batuan di daerah Kertajadi, Ciduan, Kabupaten Cianjur, Jawa Barat menggunakan metoda geomagnet. Wahana Fisika, 2(1), 37-46.

[6] BSN. (2008). Cara uji penentuan kadar air untuk tanah dan batuan di laboratorium: SNI 196: 2008. Jakatra: Indonesia.

[7] Handoko, A. D., Sembodo, S., \& Noviardi, R. (2015). Potensi dan karakteristik endapan tembaga di desa Limusgede, Kecamatan Cimerak, Kabupaten Pangandaran, Provinsi Jawa Barat. Pemaparan Hasil Penelitian Geoteknologi 2015 Meningkatkan Kualitas dan Diseminasi Hasil Penelitian Melalui Pemberdayaan Kerjasama IImiah, 19-32.

[8] Hidayat, T., Fadhhilah, \& Nasra, E. (2014). Penentuan kadar perak (Ag) dalam batuan termineralisasi menggunakan metode ekstraksi pelarut kelat ditizon dengan variasi $\mathrm{pH}$ dan waktu di wilayah tambang galian rakyat bukit Gunjo Jorong Tanjung Bungo. Bina Tambang, 1(1), 41-52.

[9] Jamaluddin, \& Umar, E. P. (2018). Identifikasi kandungan unsur logam batuan menggunakan metode XRF (x-ray fluorescence) (studi kasus: Kabupaten Buton). Jurnal Geocelebes, 2(2), 47-52.

[10] Janat, N. R., Wilopo, W., \& Indrawan, I. G. B. (2017). Kajian geologi teknik di kawasan pertambangan emas Poboya, Palu, Sulawesi Tengah. Proceeding, Seminar Nasional Kebumian Ke-10 Peran IImu Kebumian dalam Pembangunan Infrastruktur di Indonesia, 252-265. 
[11]Karyasa, I. W. (2013). Studi x-ray fluoresence dan $\mathrm{x}$-ray diffraction terhadap bidang belah batu piph asal Tejaluka. Jurnal Sains dan Teknologi, 2(2), 204-212.

[12] Kim, S., \& Choi, Y. (2019). Mapping heavy metal concentrations in beach sands using GIS and portable XRF data. Marine Science and Engineering, 2(42), 1-10.

[13] Li, F., Lu, A., \& Wang, J. (2017). Modeling of chromium, copper, zinc, arsenic and lead using portable x-ray fluorescence spectrometer based on discrete wavelet transform. Internasional Journal of Environmental Research and Public Health, 14(1163), 1-11.

[14] Mibei, G. (2014). Intoduction to types and classification of rocks. Exploration for Geothermal Resources, 1-12.

[15] Noor, D. (2012). Pengantar Geologi. Bogor: Pakuan University Press.

[16] Nurhayati, I. N., Brata, N. T., \& Rochana, T. (2017). Etnoekologi masyarakat penambang emas rakyat di desa Cihonje Kecamatan Gumelar Kabupaten Banyumas. Solidarity, 6(2), 156-166.

[17] Pambudi, M. A. R., \& Suprapto. (2018). Penentuan kadar tembaga (Cu) dalam sampel batuan mineral. Jurnal Sains dan Seni ITS, 7(2), 20-23.

[18] Qodri, R. R., \& Putra, A. (2018). Studi alterasi hidrotermal dan mineralisasi batuan di sekitar mata air panas Garara Bukit Kili , Kabupaten Solok , Sumatera Barat. Jurnal Fisika Unand, 7(3), 246-252.
[19] Sari, R. K. (2016). Potensi mineral batuan tambang bukit 12 dengan metode XRD, XRF, dan AAS. ESAKTA, 2, 13-23.

[20] Setiadi, M., Sampurno, J., Kelautan, J. I., \& Tanjungpura, U. (2016). Identifikasi sebaran batuan beku di bukit koci desa Sempalai Kabupaten Sambas Kalimantan Barat dengan menggunakan metode geolistrik resistivitas. POSITRON, 6(2), 53-59. .

[21] Sudarningsih, Bijaksana, S., Wododo, \& Iskandar, I. (2017). Karakteristik mineralogi dan morfologi serta kelimpahan logam berat pada suspended sedimen sungai Citarum saat musim kemarau. Seminar Hasil Penelitian Peningkatan Kapasitas Riset: Skema Penenlitian Disertasi Doktor.

[22] Utami, E. D., Raharja, R. D., Anggara, F., \& Harijoko, A. (2016). Mineralogi dan geokimia intrusi di tambang batubara bukit Asam, Sumatera Selatan, Indonesia. Proceeding, Seminar Hasil Kebumian Ke-9 Peran Penelitian IImu Kebumian dalam Pemberdayaan Masyarakat.

[23] Wawo, R. H. A., Widodo, S., Jafar, N., \& Yusuf, F. N. (2017). Kondisi tanah pada pertambangan rakyat Poboya Palu, Provinsi Sulawesi Tengah. Jurnal Geomine, 5(3), 116-119.

[24] Wijaya, I. P. K., Lestari, W., Ariyanti, N., Pandu, J., Sifuddin, F., Utama, W., \& Bahri, A. S. (2016). Studi kelayakan perangkap CO2 berdasarkan analisa fisik sedimen (studi kasus: formasi Kabuh, Cekungan Jawa Timur Utara). Converence on Inovation and Industrial Applications (CINIA), 227-231. 